\title{
A CONDIÇÃO JURÍDICA E A RESPONSABILIDADE DA MULHER E DAS VESTAIS NO DIREITO ROMANO
}

\author{
Elaine Marcílio Santos* \\ Alessandro Hirata**
}

Resumo: O presente artigo trata da condição jurídica da mulher em Roma, a partir de fontes analisadas à luz da metodologia dialética. Primeiramente, expõe-se um panorama geral do peculiar tratamento jurídico destinado às mulheres. Depois, discorrer-se-á acerca das sacerdotisas cultoras da deusa romana Vesta, as vestais, as quais tinham uma especial condição jurídica de independência em relação aos homens, e que também podiam realizar atividades como o comércio marítimo, sendo inclusive proprietárias de embarcações de cunho comercial, conforme comprovam recentes descobertas arqueológicas na Sardenha. Assim, com os presentes dados recentemente encontrados, pretende-se contribuir com a pesquisa em direito romano.

Palavras-chave: Direito romano. Mulher. Capacidade jurídica. Direito antigo. Vestal.

\section{THE LEGAL CONDITION AND THE RESPONSIBILITY OF WOMEN AND THE VESTALS IN ROMAN LAW}

\begin{abstract}
The present article concerns about the legal condition of the women in Rome, through the analysis of legal texts and doctrine, under the light of the dialectical method. Firstly, a general scheme of the legal treatment concerning women is exposed. Secondly, this research focus on the roman Vestal, women that had an condition of legal independence regarding men, and that could also engage in other activities, some of them having also the ownership of trade vessels, as recent archeological discoveries in Sardinia show. Thus, with the present data recently found, it is intended to contribute to research in Roman law.
\end{abstract}

Keywords: Roman law. Women. Legal capacity. Ancient law. Vestal.

\section{INTRODUÇÃO}

A condição jurídica da mulher é tema de diversas pesquisas desenvolvidas por romanistas nas últimas décadas, uma vez que a mulher desempenha papel central, fundamental para a formação de um retrato histórico fiel do direito romano. Por conseguinte,

\footnotetext{
* Pró-Reitora Acadêmica da Universidade Metropolitana de Santos. Graduação em Odontologia e Direito. Mestrado e Doutorado pela Universidade de São Paulo. Pós-Doutoranda em Direito Romano pela Universidade de São Paulo. E-mail: elaine.marcilio@unimes.br.

** Professor Associado da Faculdade de Direito de Ribeirão Preto da Universidade de São Paulo. Doutor em Direito pela Ludwig-Maximilians-Universität München (Alemanha) e Livre-docente pela Universidade de São Paulo. E-mail: alessandro.hirata@usp.br.
} 
é fundamental o estudo de sua condição jurídica, a fim de melhor entender a sociedade romana, tanto em seus aspectos puramente históricos e sociais, bem como jurídicos e econômicos. Mais ainda, tem-se casos bastante interessantes de atuação feminina na atividade econômica de Roma, como, por exemplo, na navegação e no transporte de mercadorias.

Nesse contexto, as vestais desempenhavam papel especialmente característico para entender a condição jurídica da mulher em Roma. As vestais eram sacerdotisas que cultuavam a deusa romana Vesta. Era um sacerdócio exclusivamente feminino, restrito a seis mulheres escolhidas entre a idade de seis a dez anos, servindo como vestal durante trinta anos. Durante esse período, as vestais eram obrigadas a preservar sua virgindade e castidade, pois qualquer atentado a esses símbolos de pureza significariam um sacrilégio aos deuses e à sociedade romana. Além disso, também as vestais exerciam papel relevante para a atividade econômica e política em Roma, gozando de diversos privilégios.

Desse modo, após a apresentação dos temas centrais desse trabalho, devem ser fixados como objetivos gerais dessa pesquisa a caracterização e determinação das principais especificidades da condição jurídica da mulher no direito romano e, ainda, a particular condição jurídica das vestais. Já o objetivo específico é tratar da responsabilidade da mulher em geral e das vestais nos casos de transporte de mercadorias por navios, em que a mulher figure como titular da embarcação.

Tal pesquisa justifica-se pela necessidade em analisar detalhadamente a condição jurídica da mulher e, especificamente, o peculiar caso das vestais. Durante os séculos de desenvolvimento do direito romano, o tratamento jurídico da mulher apresenta diversas fases de evolução. Desse modo, é fundamental reconstruir o tratamento jurídico dispensado à mulher, nos diversos períodos históricos do direito romano. Essa reconstrução é fundamental para entender seu contexto histórico-jurídico e sua evolução.

Ainda, quanto aos métodos de pesquisa, baseou-se no estudo das fontes primárias e secundárias de direito romano sobre a mulher, bem como, acessoriamente, de outros direitos antigos. Para o desenvolvimento desta pesquisa serão utilizados os métodos dedutivos e indutivos sob uma perspectiva dialética. O método dedutivo na medida em que se parte de uma análise geral por meio de materiais decorrentes de busca bibliográfica, podendo consistir em livros, artigos científicos, artigos jurídicos, códigos de leis e literatura internacional. O 
método indutivo será utilizado na elaboração das conclusões finais da pesquisa, posto que tais conclusões terão como ponto de partida premissas particulares obtidas por meio uma organização de todo material estudado, de maneira lógica e adequada, ressaltando os pontos relevantes para que sejam retiradas as conclusões possíveis. A perspectiva dialética mostra-se eficaz à medida que proporciona o confronto dos dados teóricos, obtidos por meio da análise crítica da pesquisa bibliográfica.

Desse modo, utilizar-se-á o direito romano como fonte de direito comparado histórico, observando as diferenças cronológicas e estruturais. Deve-se ressaltar a necessidade de um estudo moderno das fontes romanas, livre das críticas interpolacionísticas e outros vícios, típicos dos estudos romanísticos do início do século XX. Assim, as fontes precisam ser analisadas exegeticamente, sem o filtro da ultrapassada Interpolationskritik.

Assim, partir-se-á da análise da condição jurídica da mulher em Roma sob aspectos generalizantes, trazendo as principais características aplicadas pelo direito romano. Em seguida, tratar-se-á das vestais e de suas características próprias e peculiares para todo a antiguidade.

\section{CONDIÇÃO JURÍDICA DA MULHER NO DIREITO ROMANO}

A condição feminina no mundo antigo foi caracterizada por uma série de limitações nos planos familiar, jurídico e político, frequentemente justificadas por uma pressuposta inferioridade biológica ou psicológica do sexo feminino (LUCREZI, 2004, pp. 3-4). Existem várias expressões latinas que fazem referência à inferioridade feminina, por exemplo: mulierum infirmitas, infirmitas muliebris animi, levitas animi, infirmitas consilii, imbecillitas sexus, forensium rerum ignorantia. Basta dizer que as mulheres romanas não tinham direito ao nome próprio. De fato, no nascimento, o homem recebia três nomes: o praenomen (por exemplo, Marco; ao todo eram cerca de vinte), o nomen (por exemplo, Tullio) e o cognomen (por exemplo, Cícero). Já a mulher recebia apenas o nome das gens a que ela pertencia, usada no feminino. Assim, a mulher era considerada não como indivíduo, mas como parte de uma unidade familiar. 
Dentre as diversas limitações à condição jurídica da mulher, podem ser citadas: a submissão da mulher, pelo casamento cum manu, a um poder pessoal do marido, análogo àquele do pater familias, a incapacidade para exercer funções públicas e para realizar alguns atos de autonomia, como o testamento, sem a participação de um tutor, a limitada capacidade para herdar e a a impossibilidade de concluir negócios de garantia em favor de terceiro.

Talamanca (1990, p. 68), declara que, salvo no tocante às obrigações tributárias, a mulher tinha total incapacidade para o direito público, em conformidade com a ideologia dominante nas cidades-estados. Dessa forma, no período republicano ela não podia ser processada nas formas do iudicium populi perante o comício centuriato, fazendo-se necessária a intervenção do pater familias quando se tratasse da aplicação de uma pena grave.

Por conseguinte, na época arcaica, a mulher era submetida ao pai e ao marido, enquanto que no final da República e na era imperial, as mulheres de condição elevada podiam levar uma vida praticamente independente, obter divórcio e casar-se novamente. Já as de classes mais baixas permaneciam sujeitas ao sexo masculino, com as exceções das prostitutas, que apesar de estarem no nível mais baixo (com exceção das mulheres escravas), tinham uma quantidade razoável de liberdade.

No entanto, não faltavam as limitações impostas pelo direito romano à capacidade jurídica das mulheres: elas não eram titulares do ius suffragii e o ius honorum, o que as impedia de ter acesso às magistraturas públicas. Mesmo para exercer direitos civis (casar, herdar, fazer um testamento), elas precisavam do consentimento de um tutor, ou seja, de homens que exerciam proteção sobre elas.

Com a evolução da sociedade romana, afirma Lucrezi (2004, pp. 4-5), pelo menos desde os primeiros séculos da República, foram reconhecidos vários direitos à mulher romama - cidadania, geral capacidade patrimonial e negocial, dentre outros. Dessa forma, esta (filia, sponsa, uxor, mater ou vidua) ocupou uma posição privilegiada quando comparada a muitas outras mulheres da antiga civilização mediterrânea.

Desse modo, foi instituído o casamento sine manu, o qual determinou uma maior independência da mulher que, embora continuasse sob o poder do pai, não se submetia à potestas do marido ou dos homens da família adquirida. No campo do direito privado, também foi negada às mulheres a patria potestas, prerrogativa exclusiva 
do homem e, consequentemente, a capacidade de adotar. O princípio é expresso, no direito clássico, pelo jurista romano Gaio em suas instituições: "Feminae vero nullo modo adoptare possunt, quia ne cuidem naturales liberos in potestate habent"1 (Gai. 1, 104). Novamente, com Gaio, aprendemos que às mulheres, com exceção das Virgens Vestais, no período arcaico não eram permitidas fazer um testamento. No entanto, essa última limitação já tinha sido revogada na era republicana.

Cantarella (2015, pp. 133-146) afirma que, diferentemente das mulheres gregas, cuja emancipação permaneceu essencialmente inalterada até o helenismo, a condição das mulheres romanas sofreu mudanças muito profundas ao longo dos séculos. De fato, a partir de uma total falta de autonomia, na idade de Augusto, as mulheres alcançaram um bom grau de emancipação e a causa da mudança na condição feminina foi a sucessão quase ininterrupta de dois séculos de guerra. A expansão de Roma levou à dizimação da população masculina e um número crescente de mulheres, vez que muitos pais e maridos perdim-se nas guerras. Assim, as mulheres se viram independentes, mesmo na gestão do patrimônio comercial e familiar.

No final da República e durante o Principado, à mulher foi atribuída a plena capacidade processual nos iudicia publica, seja nas quaestiones perpetuae, seja na cognitio criminal. No sistema da cognitio, ademais, ela podia, em alguns casos, dar início ao processo. Assim, as condições sociais da mulher romana entre no final do século I mostram que elas eram agora muito diferentes daquelas dos primeiros séculos da República. A muitas imperatrizes romanas dessa época, por exemplo, é atribuído o título de Augusta, que foi dado a Lívia somente após a morte de seu marido Augusto. A grande figura de uma mulher é a de Plotina, esposa de Trajano, que acompanhara o marido na guerra e, após a morte do imperador, aderiu voluntariamente à sua vontade política testamentária, permitindo a Adriano obter a sucessão sem oposição.

\section{A PARTICIPAÇÃO FEMININA NA ATIVIDADE ECONÔMICA: NAVEGAÇÃO}

Dentro do contexto socioeconômico em que se insere a figura feminina, com inevitáveis efeitos jurídicos, cabe destacar a atuação da mulher na economia romana. Apesar

\footnotetext{
${ }^{1}$ Gai 1, 104: “As mulheres não podem adotar, porque não têm poder livre nem mesmo sobre os filhos naturais" (Tradução nossa).
} 
das conhecidas limitações e proteções para as mulheres ${ }^{2}$, é possível encontrar nas fontes romanas uma participação ativa e determinante das mulheres, como, por exemplo, comandantes de navios e responsáveis pelo transporte de mercadorias.

O envolvimento das mulheres na titularidade e gestão de companhias de navegação é amplamente atestado em algumas fontes jurídicas do século III d. C. Essas fontes mostram que, na era de Severo, havia também uma forte presença feminina na atividade naval inerente ao transporte e comercialização de mercadorias, nascida com uma vocação distintamente masculina.

Na realidade, a participação de mulheres em atividades de armamento havia encontrado um primeiro impulso após uma provisão normativa do imperador Cláudio, a qual Suetônio testemunha em uma passagem tirada das Vidas dos doze Césares:

Suet., Claud., 18-19: Urbis annonaeque curam sollicitissime semper egit. Cum Aemiliana pertinacius arderent, in diribitorio duabus noctibus mansi ac deficiente militum ac familiarum turba auxilio plebem per magistratus ex omnibus vicis convocavit ac positis ante se cum pecunia fiscis ad subveniendum hortatus est, rapraesentans pro opera dignam cuique mercedem. Artiore autem annona ob assiduas sterilitates detentus quodam medio foro a turba conviciisque et simul fragminibus panis ita infestatus, ut aegere nec nisi postico euadere in Palatium valuerit, nihil non excogitavit ad invehendos etiam tempore hiberno commeatus. Nam et negotiatoribus certa lucra proposuit suscepto in se damno, si cui quid tempestates accidisset, et naves mercaturae causa fabricantibus magna commoda constituit pro condicione cuiusque: civi vacationem legis Papiae Poppaeae, Latino ius Quiritium, feminis ius IIII liberorum; quae constituta hodieque servantur.

Nessa longa passagem, Suetônio faz um relato das atividades realizadas pelo imperador Cláudio para os cuidados da cidade e o fornecimento de trigo. Segundo o autor, o imperador ficou tão impressionado com as situações críticas decorrentes da escassez de suprimentos alimentares ciclicamente ocorridas em Roma (conta um episódio vivido por Cláudio, que precisou refugiar-se no palácio, em virtude de um tumulto realizado pela multidão no Fórum durante uma manifestação de protesto por a falta de comida), que veio a intervir com medidas capazes de garantir ganhos seguros aos negociadores (certo lucro),

\footnotetext{
${ }^{2}$ São diversas as limitações e os instrumentos de proteção às mulheres, dentre os quais há especial destaque a tutela mulierum (GIRARD, 1929, pp. 212-213; VOLTERRA, 1988, pp. 108-111; MOREIRA ALVES, 2014, pp. 692-694).
} 
atraindo para si eventuais prejuízos suportados, caso perdessem os bens como resultado de um naufrágio. Além disso, também concedeu muitas vantagens (magna commoda), de acordo com as respectivas condições, àqueles que construíssem navios de carga: aos cidadãos romanos foi concedida a dispensa pela Lex Poppea, aos latinos foram garantidas as prerrogativas legais previstas direito quiritário; e finalmente para as mulheres, foi concedido o ius quatuor liberorum (ORTU, 2018, pp. 96-98).

Trata-se de medida bastante incisiva, que concedeu às mulheres construtoras de navios mercantis a completa autonomia patrimonial anteriormente concedida às mulheres com base no ius quatuor liberorum. Então Claudio, com a intenção de garantir o fornecimento constante de trigo e garantir constantemente os suprimentos anuais, também concedeu privilégios especiais às mulheres construtoras de navios que deveriam usar no transporte de mercadorias úteis (ORTU, 2018, p. 97).

O conteúdo das medidas de Cláudio também encontra respaldo nas fontes jurídicas que chegaram até nós, complementando as informações transmitidas por Suetônio. Nesse sentido, é relevante o testemunho de Gaio, nas suas Institutas, e também de Ulpiano, nos Tituli ex corpore Ulpiani, relatando um edito de Cláudio, que trata dos privilégios aos latinos:

Gai. 1.32c: Item edicto Claudii Latini ius Quiritium consecuntur, si navem marinam aedificaverint, quae non minus quam decem milia modiorum frumenti capiat, eaque navis vel quae in eius locum substituta sit, sex annis frumentum Romam portaverit.

Tit. Ulp. 3.6: Nave Latinus civitatem Romanam accipit, si non minorem quam decem milium modiorum navem fabricaverit, et Romam sex annis frumentum portaverit, ex edicto divi Claudii.

Ambas as passagens não se referem às outras duas categorias de destinatários da provisão indicada por Suetônio, provavelmente porque no contexto em que foram inseridas era especificamente apenas a concessão do ius Quiritium aos latinos.

No entanto, ao ler os dois textos jurídicos, surgem alguns dados interessantes que, de uma forma mais extensa, certamente também podem remeter-se aos assuntos mencionados na passagem de Suetônio, ou seja, em relação aos cidadãos romanos isentos de pagar o imposto sobre os celibatários previsto pela Lex Poppea e as mulheres beneficiárias de autonomia patrimonial, graças à concessão do ius quatuor liberorum, por terem construído navios para o 
transporte de mercadorias (ORTU, 2018, p. 98). De fato, pelos depoimentos de Gaio e Ulpiano, fica claramente especificado que os navios em questão deveriam ter uma tonelagem capaz de permitir o armazenamento de dez mil modius ${ }^{3}$ de trigo e que a atividade de transporte de grãos deveria ser realizada por seis anos.

Assim, a autonomia patrimonial feminina, que já havia sido reconhecida para as virgens vestais, como será especificado posteriormente, bem como em outras categorias restritas de mulieres, nessa conjuntura parecia estar intimamente ligada à construção de navios de grande porte para o transporte de trigo. Desse ponto de vista, as mulheres receptoras das mercadorias, conforme a determinação de Claudio, poderiam, sem dúvida, qualificar-se como dominae navium.

Ainda, em um rescrito de Diocleciano do ano de 293 d. C., é feita clara referência às mulheres armadoras, a quem era dado claramente o poder de nomeação do magister navis para as atividades das empresas navais administradas por elas pessoalmente (ORTU, 2018, p. 98): C. 4.25.4, Impp. Diocl. et Maxim. AA. Et CC. Antigonae. (a. 293): Et si a muliere magister navis praepositus fuerit, ex contractibus eius ea exercitoria actione ad similitudinem institoriae tenetur D. XVI K. Nov. Sirmi A.A. Conss.

O rescrito diz respeito ao caso de uma mulher chamada Antígona, que, depois de conferir a praepositio ao magister navis, propôs uma pergunta ao imperador sobre os limites de sua responsabilidade após tal designação do magister navis.

A solução para a pergunta ao imperador foi imediata e precisa: Antígona, por meio da actio exercitoria, assimilável nessa circunstância à actio institoria, poderia ser chamada a responder pelos atos praticados por seu preposto em virtude da praepositio conferida (ORTU, 2018, p. 99). Assim, o rescrito reconhece uma subjetividade para com a mulher que, aos olhos de Diocleciano e sua chancelaria, foi considerada, de maneira totalmente inovadora, no campo dos negócios relacionados à administração de empresas de transporte. Com o reescrito, a mulher encarregada de uma empresa marítima foi reconhecida com o papel de centro direto de imputação de interesses e responsável direta pelos atos de negociação praticados por aqueles que haviam investido na praepositio (ORTU, 2018, p. 99).

\footnotetext{
${ }^{3}$ Unidade de volume utilizada em Roma, correspondente a aproximadamente 83/4 litros.
} 
Do mesmo modo, é possível comprovar a presença nas empresas de navegação de mulheres com o papel de dominae navium, ou seja, como chefes atividades de transporte marítimo e também diretamente responsáveis pelas ações realizadas pelos seus praepositi, em fragmentos como o de Ulpiano: D. 14.1.1.16 (Ulp. 1. 28 ad ed.): Parvi autem refert, qui exercet masculus sit an mulier, pater familias an filius familias vel servus: pupillus autem si navem exerceat, exigemus tutoris auctoritatem.

O jurista reitera que pouco importa se o proprietário é homem ou mulher, pai de família, filho sob seu poder ou servo (masculus, mulier, pater familias, filius vel servus). Ulpiano ainda especifica que, se for um pupilo a operar uma companhia de navegação, ele precisará da autorização do responsável (tutor).

Um fato interessante surge da leitura do fragmento. De fato, o jurista atribui à mulher a possibilidade de ser exercitadora navis e, portanto, de desempenhar um papel principal na administração da companhia marítima, enquanto não menciona a possibilidade de a mulier ser a destinatária de um praepositio como magister navis, isto é, o papel de capitã do navio que implicava não apenas a suposição da conduta do barco, mas também e, acima de tudo, a gestão dos negócios dentro dos limites da praepositio. Segundo Petrucci (2017, p. 35), esse silêncio está bastante alinhado a todas as descobertas das fontes antigas, devendo ser interpretado mais do que uma exclusão legal, da qual faltam mais evidências, e sim como uma exclusão em nível econômico-social, dadas as dificuldades práticas para se executar essa função, à qual a tarefa de navegar no navio estava frequentemente conectada.

Essa situação, no entanto, não encontra paralelos na chamada empresa terrestre, pois no fragmento de Ulpiano em D. 14, 3, 7, 1, lê-se:

D. 14.3.7.1 (Ulp. 28 ad ed.): Parvi autem refert, quis sit institor, masculus an femina, liber an servus proprius vel alienus. Item quis sit qui praeposuit: nam et si mulier praeposuit, competet institoria exemplo exercitoriae actionis et si mulier sit praeposita, tenebitur etiam ipsa. Sed et si filia familias sit vel ancilla praeposita, competit institoria actio.

Nessa passagem, o jurista relata que, na ação contra o empresário terrestre, ambos os sujeitos, chefe e preposto, poderiam ter sido mulheres. Ou seja, tem-se a confirmação do princípio segundo o qual, nas empresas terrestres, o papel da mulier pode ser tanto de instituidora como de preposta e administradora (ORTU, 2018, p. 101). 


\section{AS SACERDOTISAS VESTAIS}

O sacerdócio das vestais consistia em seis sacerdotisas escolhidas quando tinham de seis a dez anos de idade e que permaneciam por pelo menos trinta anos no serviço sacerdotal (GARDNER, 1986, p. 43; GARDNER, 1995, p. 50; CANCIK-LINDEMAIER, 2002, pp. 132-133; BÄTZ, 2012, p. 86). Sua principal tarefa era guardar o fogo no templo de Vesta, que nunca podia se apagar, e buscar a água da fonte sagrada da ninfa Egéria, usada para limpar o templo. As vestais também eram responsáveis por fazer a mola salsa (uma mistura de água salgada e farinha de grãos) e o material (cinzas de bezerros por nascer) necessários para certos atos de culto.

Em relação ao culto, as vestais estavam submetidas ao Colégio de Pontífices e em particular ao Pontifex maximus (BERGER, 1953, p. 762). Quanto ao seu status social pessoal, as vestais tinham condições semelhantes às de um homem romano, tendo, por outro lado, diversos outros privilégios. Porém, durante o sacerdócio, as vestais eram obrigadas ao dever de castidade. A perda da virgindade de uma vestal era considerada um presságio ameaçador para a comunidade romana: uma vestal que perdesse sua virgindade seria removida do sacerdócio e enterrada viva (SCHALLES, 2002, p. 51; MEKACHER, 2006, p. 73).

Quando uma vestal morria ou deixava o sacerdócio, sua sucessora era nomeada pelo Pontifex maximus. Os detalhes desse processo são bastante obscuros, mas remontam principalmente ao texto de Aulo Gélio, do século II d. C. ${ }^{4}$. Também nesse fragmento, é possível identificar os requisitos de exigibilidade para uma vestal. Assim, a menina não podia ter menos de seis anos e nem mais de dez anos, nem poderia apresentar um erro de fala ou qualquer deficiência física. Ainda, seu pai e sua mãe deveriam estar vivos, sendo que ambos não poderiam ter sido escravos anteriormente, mesmo que fossem libertados e emancipados. Da mesma forma, seus pais não podiam ganhar a vida com negotia sordida (ou seja, venda de artesanato ou varejo de pequenas mercadorias). Ainda, Gélio acrescenta que, para privar uma jovem de sua vocação vestal, bastava uma de suas irmãs já ser uma vestal, ou o pai ter um papel de culto em Roma, morar fora da península itálica ou ter três filhos.

\footnotetext{
${ }^{4}$ Noctes Atticae 1.12. Virgo Vestae quid aetatis et ex quali familia et quo ritu quibusque caerimoniis ac religionibus ac quo nomine a pontifice maximo capiatur et quo statim iure esse incipiat, simul atque capta est; quodque, ut Labeo dicit, nec intestato cuiquam nec eius intestatae quisquam iure heres est.
} 
Ao se tornar uma vestal, a jovem deixava a patria potestas (VOLTERRA, 1988, p. 85) de seu pai ou avô e se torna juridicamente totalmente independente. $\mathrm{O}$ antigo entendimento que ela estaria submetida à patria potestas do Pontifex maximus como pai ou marido simbólico provou estar errada (ORTU, 2018, p. 27).

Desse modo, a vestal tinha poder ilimitado sobre sua propriedade, assim como um status extraordinário, já que outras mulheres, pelo menos no início do período imperial, sempre precisavam do consentimento de um tutor do sexo masculino para poder concluir transações legalmente válidas (ORTU, 2018, p. 27).

Por conseguinte, ao deixar a sua associação familiar, a vestal não tinha mais parentes legais. De acordo com Labeão ${ }^{5}$, ela deixa de fazer parte da sucessão natural e só poderia herdar mediante disposição testamentária (neque heres est cuiquam intestato). Do mesmo modo, ela também apenas transferiria seu patrimônio por meio de testamento (neque intestatae quisquam). Se ela não deixasse sua vontade expressa por um testamento, seu patrimônio passaria a ser propriedade pública após sua morte.

Ainda, entende-se que a vestal não pertencia a nenhum núcleo familiar. Isso porque, a sacerdotisa era considerada um parente simbólico ou ideal de todos os cidadãos romanos e, portanto, não podia ter relações familiares com indivíduos determinados (CANCIKLINDEMAIER, 2002, pp. 132-133). Nesse sentido, o suprimento de fogo no templo de Vesta poderia representar uma analogia à manutenção do fogo da lareira em uma casa particular, de modo que as vestais pudessem ser vistas como a Mater familias simbólicas do povo romano (SCHALLES, 2002, p. 52; MEKACHER, 2006, p. 73). Essa hipótese também foi levantada por Plínio, o Jovem ${ }^{6}$ :

Epistulae 7.19.1-2: 1. Angit me Fanniae valetudo. Contraxit hanc dum assidet Iuniae virgini, sponte primum - est enim affinis -, deinde etiam ex auctoritate pontificum. 2. Nam virgines, cum vi morbi atrio Vestae coguntur excedere, matronarum curae custodiaeque mandantur. Quo munere Fannia dum sedulo fungitur, hoc discrimine implicita est.

\footnotetext{
5 A referência à opinião de Labeão é feita por Gélio: Noctes Atticae 1.12.18. Praeterea in commentariis Labeonis, quae ad duodecim tabulas composuit, ita scriptum est: "Virgo Vestalis neque heres est cuiquam intestato, neque intestatae quisquam, sed bona eius in publicum redigi aiunt. Id quo iure fiat, quaeritur."

${ }^{6}$ Epistulae 7.19.2.
} 
No fragmento, Plínio indica que as vestais doentes não eram cuidadas por suas colegas ou parentes, mas sim confiadas aos cuidados de uma mulher selecionada pelo Pontifex maximus. Tais hipóteses são muito especulativas, pois, por um lado, o verdadeiro significado do fogo no templo de Vesta é desconhecido e, por outro lado, a vestal Iúnia mencionada por Plínio foi cuidada justamente por sua cunhada Fannia.

A maioria das vestais aparentemente pertencia à alta classe senatorial, como pode ser visto nos nomes tradicionais que indicam pertencer a famílias de nobreza, por exemplo, Aemilia, Claudia, Cornelia e Licínia (MEKACHER, 2006, p. 74). Essa suposição também é apoiada pelo fato de que as vestais geralmente tinham grandes fortunas. A influência política exercida por algumas vestais (por exemplo, Licínia, que apoiou sua parente Murena na campanha eleitoral em 63 a. C.) também pressupunha que elas pertencessem a uma classe social mais alta.

\title{
5. VESTAIS TITULARES DE EMBARCAÇÕES
}

Quanto ao interessante caso de vestal responsável por navios, exemplar o recente estudo de Ortu (2018), sobre a Vestal Máxima Flavia Publicia. Trata-se de perfeito exemplo de como uma inscrição (fonte primária) pode dar ensejo a descobertas jurídicas. A placa de bronze encontrada recentemente durante o trabalho de modernização do cais do porto comercial de Porto Torres, na Sardenha, em 2007, e analisada em sua obra revela a interessante figura de Flavia Publicia, Vestal Máxima que teve diversos privilégios e uma vida jurídica representativa, em meados do século III d. C. A placa de bronze descoberta contém a seguinte inscrição:

\author{
FLAVIAE · \\ PVBLICIAE · \\ $\mathrm{V}$ (imagem) $\mathrm{V}$ \\ MAXIMAE \\ IMMVNIS
}

POR NAVCELLA · MARINA · CVNBVS $\cdot$ PORTENSIS · 


\section{PARASEMO $\cdot$ PORFÍRIS · EVDROMVS ·}

Assim, o contex to que emerge da análise do conteúdo da placa é muito claro: o barco do porto com o sinal Porphyris (é) de Flavia Publicia, virgem vestal máxima, sendo imune o (seu) barco naval; com citação final de Eudromus, servus da sacerdotisa. Portanto, desde uma primeira leitura, já é clara a alusão a uma nova imunidade tributária, completamente desconhecida, concedida à vestal máxima Flavia Publicia, proprietária de uma naucella marinha e do escravo Eudromus (ORTU, 2018, p. 74).

O conteúdo do texto da placa é de interesse jurídico indiscutível, pois além de mencionar a imunidade que consiste na isenção do pagamento de taxas portuárias (a portoria) concedida a uma vestal, implica também a existência de atividades comerciais realizadas pela Flavia Publicia, por meio de uma estrutura bem definida, que certamente seguiu os modelos organizacionais legais em voga, na era imperial, para empresas de transporte.

A descoberta da tábua de bronze no norte da Sardenha, também atesta a existência de tráfego comercial realizado pela Flavia Publicia na ilha, localizada no Mare Sardum em uma posição estratégica, no caminho em direção ao Colunas de Hércules. Ainda, era usado como plataforma para o tráfego marítimo mediterrâneo entre o leste (a partir da Síria) e o oeste (em Gades), bem como um ponto de partida para o transporte de trigo da Sardenha para Ostia, particularmente intensificado na era de Constantino. Também, era um ponto de trânsito para o trigo africano que chegava a Ostia via Sardenha em virtude dos laços consolidados entre a África e a ilha, já iniciados no período republicano e revigorados na era imperial, e provavelmente também de sal (ORTU, 2018, p. 74).

Além disso, vale uma reflexão sobre o tipo de atividade realizada pela vestal máxima Flavia Publicia como proprietária de um cunbus Portuensis em Turris Libisonis que, com toda a probabilidade, estava conectado, como embarcação de apoio, a um grande navio de carga ainda de propriedade da sacerdotisa, atracado fora da área portuária (ORTU, 2018, p.107).

Com o conteúdo da placa de bronze, descobre-se que Flavia Publicia era uma domina navium, um papel que, em sua época, como relatado no início desse texto, compartilhava muitas outras mulheres, perfeitamente enquadradas nas estruturas organizacionais das 
empresas navais de transporte e comercialização de mercadorias. Vale relembrar o decreto de Cláudio que demonstra a atuação feminina na construção de navios mercantes para fins relacionados ao fornecimento de grãos (ORTU, 2018, p.103).

O contexto em que a Flavia Publicia se enquadra, na sua posição de domina navium, é indubitavelmente interessante do ponto de vista jurídico. Isso porque, graças aos textos citados anteriormente ${ }^{7}$, as regras apontadas nos referidos fragmentos também se tornaram aplicáveis às mulieres proprietárias de navios, bem como titulares de atividades de transporte comercial marítimo. A vestal máxima Flavia Publicia, assim como as mulieres mencionadas no edito de Claudio, participava diretamente de suas atividades na Sardenha no transporte de grãos e sal (ORTU, 2018, p. 104). Em virtude de sua posição sacerdotal, de seus méritos amplamente reconhecidos publicamente por uma série de epígrafes a ela dedicadas e, principalmente, porque a Vestalia Maxima contribuiu com seu navio para o suprimento de Roma, Flavia Publicia recebeu imunidade em relação ao pagamento de portorias por mercadorias transportado de Turris Libisonis para Ostia.

Obviamente, essa atividade comercial não pôde ser gerenciada com a presença física de Flavia Publicia. Portanto, para o gerenciamento da atividade de transporte de grãos realizada pela Vestal, era necessário fazer referência a números de pessoal especializado responsável por conduzir os barcos e, acima de tudo, que desempenhassem um papel ativo nas negociações inerentes ao tipo de atividade comercial realizada. A presença do Eudromus servus é funcional e relevante para esse fim. O fato do escravo ser nominalmente mencionado na tabela de imunitatis pode levar a pensar que ele desempenhava a função de gerente comercial do transporte de grãos organizado com o uso dos navios de Flavia Publicia a qual, do ponto de vista jurídico, pode ser considerada não apenas uma domina navium, mas também em como exercitador navis (ORTU, 2018, p. 104).

Assim, o papel da vestal nas atividades realizadas na Sardenha obviamente não era do tipo religioso, mas era do tipo comercial, pois Flavia Publicia era encarregada de uma verdadeira empresa de transporte de grãos e, provavelmente, também de sal, a fim de contribuir com os suprimentos de Roma. Como um resultado disso, também parece clara a função Eudromus, servus da sacerdotisa, atuando, nesse contexto, como navis

\footnotetext{
${ }^{7}$ Vide item 2.1 supra.
} 
magister de Flavia Publicia, em razão de uma praepositio que delineou os limites da atividade comercial.

Ortu (2018, p. 105) discorda da opinião que o escravo não era o "marinheiro ou piloto real" dos barcos da sacerdotisa, como afirma Gasperetti (2009, p. 272), mas defende ser Eudromus o comandante e também responsável pela atividade comercial realizada pela vestal. Não por acaso o seu nome foi mencionado expressamente na inscrição, pois seu papel foi preeminente na organização da compra e transporte de trigo da Sardenha com base nas indicações precisas fornecidas pela praepositio.

Como se sabe, o praepositus recebe do proprietário do navio uma série de diretrizes que também deveriam ser levadas em consideração pelos terceiros contratantes na conclusão das transações e contratos legais. Nesse sentido, vale lembrar o conteúdo de um fragmento de Ulpiano, referindo-se a uma preposição instintiva:

D. 14.3.11.2-4 (Ulp. 28 ad ed.): De quo palam proscriptum fuerit, ne cum eo contrahatur, is praepositi loco non habetur: non enim permittendum erit cum institore contrahere, sed si quis nolit contrahi, prohibeat: ceterum qui praeposuit tenebitur ipsa praepositione. Proscribere palam sic accipimus claris litteris, unde de plano recte legi possit, ante tabernam scilicet vel ante eum locum in quo negotiatio exercetur, non in loco remoto, sed in evidenti. litteris utrum Graecis an Latinis? puto secundum loci condicionem, ne quis causari possit ignorantiam litterarum. certe si quis dicat ignorasse se litteras vel non observasse quod propositum erat, cum multi legerent cumque palam esset propositum, non audietur. Proscriptum autem perpetuo esse oportet: ceterum si per id temporis, quo propositum non erat, vel obscurata proscriptione contractum sit, institoria locum habebit. proinde si dominus quidem mercis proscripsisset, alius autem sustulit aut vetustate vel pluvia vel quo simili contingit, ne proscriptum esset vel non pareret, dicendum eum qui praeposuit teneri. sed si ipse institor decipiendi mei causa detraxit, dolus ipsius praeponenti nocere debet, nisi particeps doli fuerit qui contraxit.

O jurista destacou que, no local onde a atividade foi realizada, o conteúdo e os limites do praepositio deveriam ser divulgados de forma visível e divulgada publicamente. Era, portanto, uma espécie de anúncio para a tarefa (ORTU, 2018, p. 106).

\section{CONCLUSÕES}


Ao fim do presente estudo, é possível alcançar algumas conclusões. Não restam dúvidas de que as mulheres tinham condição jurídica limitada no direito romano, como ricamente testemunhado pelas fontes que chegaram até os dias atuais. Porém, as fontes também revelam casos de mulheres que participavam ativamente de vida jurídica e econômica de Roma em alguns setores com, por exemplo, na navegação. Assim, não ocupam uma posição de total afastamento, mas são de fundamental importância para o contexto socioeconomico.

Nesse contexto, destacam-se as vestais: sacerdotisas da deusa romana Vesta que desfrutavam de uma posição jurídica muito peculiar, com muitos privilégios os quais, muitas vezes, eram superiores àqueles concedidos aos homens. As vestais eram exceções às mulheres comuns, mas semelhantes a essas mulheres especiais.

Também na navegação, as vestais apresentavam certo destaque, assim como outras mulheres, como comprovam a obra de Rosanna Ortu (2018) e a vida da vestal máxima Flavia Publicia.

Nesse contexto, nota-se que o incentivo à construção de navios mercantes de um certo tamanho para mulheres as quais, como os latinos e os cidadãos romanos, os usavam por seis anos para o transporte de trigo para fins de Annona, remonta ao imperador Cláudio. Tal fato certifica não apenas a atribuição do privilégio legal concedido às mulieres que desfrutavam do ius quatuor liberorum, mas também que, a partir daquele momento, haveria dominae navium engajadas no comércio e transporte de grãos para suprir as necessidades de Annona. Assim, tem-se uma imunidade tributária no transporte de grãos da Sardenha para Roma - principal descoberta da obra de Ortu (2018),

O modelo organizacional das companhias de navegação previa uma estrutura básica liderada pelo armador chamado exercitor navis, o qual geralmente conferia um praepositio a um magister navis. Este, por sua vez, poderia ser um sujeito ou um sujeito sui iuris, a fim de conduzir negociações relacionadas às atividades da empresa. Contudo, tal modelo organizativo também previa o envolvimento de mulheres, as quais poderiam assumir o papel de exercitor navis e, desse modo, poderiam ser responsabilizadas de maneira ilimitada, conforme previsão nos editos, em caso de inadimplemento das obrigações contratuais 
assumidas pelos subordinados. E, tal responsabilidade ilimitada, atingia tanto as mulheres quanto as vestais, ainda que estas fossem titulares de diversos privilégios, como já ressaltado.

Contudo, não há fontes que atestem mulieres ativas no papel de magister navis. Podese presumir, então, que as mulheres poderiam estar isentas de assumir esse papel devido à falta de experiência prática na arte da navegação. Pode-se presumir, ainda, a inexistência exclusão legal, de fato, que excluísse a priori a assunção do papel de magister navis pelas mulieres.

De todo modo, pode-se entender que o modelo organizacional descrito poderia ser mais ou menos articulado e também poderia envolver o uso de servidores ou outros subordinados (homens e mulheres) com características peculiares. Tudo isso traz à luz, nos dias de hoje, uma nova visão sobre o papel das mulheres no direito e na sociedade romana antiga.

\section{REFERÊNCIAS BIBLIOGRÁFICAS}

BÄTZ, Alexander. Sacrae virgines: Studien zum religiösen und gesellschaftlichen Status der Vestalinnen. Paderborn: Ferdinand Schöningh, 2012.

BERGER, Adolf. Encyclopedic Dictionary of Roman Law. Philadelphia: The American Philosophical Society, 1953.

CANCIK-LINDEMAIER, Hildegard. Vestalin. In CANCIK, Hubert; SCHNEIDER, Helmuth (ed). Der Neue Pauly: Enzyklopadie der Antike herausgegeben. v. 12. Stuttgart: Metzler, 2002. pp. 132-133.

CANTARELlA, Eva. Passato prossimo: Donne romane da Tacita a Sulpicia. Milano: Feltrinelli, 2015.

GARDNER, Jane. Women in Roman law and society. London: Croom Helm, 1986. 
Frauen im antiken Rom: Familie, Alltag, Recht. München: C.H.Beck, 1995.

GASPERETTI, Gabriella. Una tabella immunitatis dal porto di Turris Libisonis. In MASTINO, Attilio; SPANU, Pier Giorgio; ZUCCA, Raimondo (coord.). Naves plenis velis euntes. Roma: Carocc 2009. pp. 266-277.

GIRARD, Paul Frederic. Manuel Élémentaire de Droit Romain. 8 ed. Paris: Rousseau et Cie, 1929.

LUCREZI, Francesco. La violenza sessuale in diritto ebraico e romano: Studi sulla “Collatio" II. Torino: Giappichelli, 2004.

MEKACHER, Nina. Die vestalischen Jungfrauen in der römischen Kaiserzeit. Wiesbaden: Reichert, 2006.

MOREIRA ALVES, José Carlos. Direito Romano. 16 ed. Rio de Janeiro: Forense, 2014.

ORTU, Rosanna. Condizione giuridica e ruolo sociale delle vestali in età imperiale: la vestale Massima Flavia Publicia - I - Le immunità. Ortacesus: Sandi, 2018.

PETRUCCI, Aldo. Note sui 'marchi di produzione' e dati delle fonti giurisprudenziali.

Bullettino dell'istituto di Diritto Romano 'Vittorio Scialoja, Roma, v. 111, serie 4 - 7, pp. 21-40, 2017.

SCHALLES, Christiane. Die Vestalin als ideale Frauengestalt: Priesterinnen der Göttin Vesta in der bildenden Kunst von der Renaissance bis zum Klassizismus. v. 2. Göttingen: Cuvillier, 2002.

TALAMANCA, Mario. Istituzioni di diritto romano. Milano: Giuffrè, 1990.

VOLTERRA, Edoardo. Istituzioni di diritto privato Romano. Roma: La Sapienza, 1988. 
